\title{
REMINERALIZATION EFFECT OF EGG SHELL POWDER AND NOVAMINE ON INITIAL CARIES-LIKE LESIONS IN YOUNG PERMANENT TEETH (IN-VITRO STUDY)
}

\author{
Eman O. Mohamed ${ }^{1 * B D S}$, Aly A. Sharaf ${ }^{2}$ PhD, Dalia M. Talaat ${ }^{\text {PhD, }}$ Dina A. Nagui ${ }^{\text {PhD }}$.
}

\begin{abstract}
INTRODUCTION: Despite the cariostatic effect of fluoride, the continuous use of fluoridated toothpastes increases the risk of dental fluorosis. Therefore, new safe alternative technologies of teeth remineralization must be introduced to arrest dental caries and remineralize the early enamel carious lesions.

OBJECTIVES: The aim of the study was to evaluate the remineralizing effect of eggshell powder and novamine on initial caries-like lesions in young permanent teeth compared to fluoride.

MATERIALS AND METHODS: A total of 96 permanent teeth were selected. Each Tooth was coated with nail varnish, leaving squares of $4 \times 4$ $\mathrm{mm}$. Each tooth was sectioned into 2 halves longitudinally in a buccolingual direction through the center of the window to obtain a mesial and a distal half (192 specimens). One half was treated and the other half was remained untreated to serve as its negative control. Teeth were assigned into three groups according to treatment agent; group I (eggshell powder solution), group II (novamine toothpaste) and group III (fluoride toothpaste) .Specimens were immersed in the demineralizing solution for 72 hours to produce artificial carious lesions on the exposed enamel surface.

RESULTS: There was a statistically significant mean microhardness and lesion depth values between test subgroups IA (eggshell powder), IIA (novamine) and their controls $(\mathrm{P}<0.001)$. There was no statistically significant difference in mean microhardness and lesion depth values between the test subgroup IIIA (fluoride) and its control ( $>0.001)$. There was statistically significant difference in mean percent difference values of enamel microhardness among three groups $(\mathrm{P}<0.001)$. There was no statistically significant difference in mean percent difference values of lesion depth between the three groups $(\mathrm{P}>0.001)$.
\end{abstract}

CONCLUSION: Both eggshell powder and novamine were effective for remineralization of initial caries-like lesions of young permanent teeth. KEYWORDS: Remineralization, eggshell powder, novamine, fluoride.

RUNNING TITLE: Remineralization effect of eggshell powder and novamine.

1 Bachelor of Dentistry, Faculty of Dentistry, Alexandria University, Alexandria, Egypt.

2 Professor of Pediatric Dentistry, Faculty of Dentistry, Alexandria University, Alexandria, Egypt.

3 Associate Professor of Pediatric Dentistry, Faculty of Dentistry, Alexandria University, Alexandria, Egypt.

4 Lecturer of Oral Biology, Faculty of Dentistry, Alexandria University, Alexandria, Egypt.

* Corresponding author

E-mail:emanosama282@yahoo.com

\section{INTRODUCTION}

Dental caries is considered one of the most common chronic diseases throughout the whole world (1). The World Health Organization (WHO) in 2003 reported that there is an international widespread distribution of global caries epidemiology with $60-90 \%$ caries prevalence among schoolage children. It also affirmed that dental caries in 12-yearsolds is increasing in developing countries (2). Moreover, Selwitz et al. in 2007 (3) concluded that the prevalence of dental caries is a continuous public health problem in most developed countries.

Rebuilding of carious lesions through tooth preparation and use of restorative material is an irreversible cycle which results in loss of tooth structure over time (4). Preventive treatment and early intervention of initial carious lesions are the key components of the recent dental caries management (5). Remineralizing agents play an important role in improving the remineralization process and prevention of dental caries (6).
Fluoride is an effective remineralizing agent for caries prevention. It has an important role in increasing the resistance of tooth structure to demineralization by acids through the formation of fluoroapatite crystals in enamel $(6,7)$. On the other hand, the continuous use of fluoridated toothpastes increased the risk of dental fluorosis during the period of dental development (7). Wright et al. in 2014 (8) systematically reviewed fluoride toothpaste efficacy and safety in children younger than 6 years. It was concluded that fluoride toothpaste is effective in prevention of dental caries. However, ingestion of pea-sized amounts or more lead to increasing the risk of mild fluorosis.

Egg shell powder (ESP) is a natural source of calcium ions (9). ESP contains 94\% calcium phosphate, $4 \%$ organic matter, $1 \%$ magnesium carbonate and low concentration of strontium, fluoride, manganese, zinc and copper ions (10). ESP has an important role in bone and dental metabolism (11). Researchers proved that ESP has the ability to form high quality hydroxyapatite $(12,13)$. Kattimani et al. in 2014 (13) revealed that eggshell derived hydroxyapatite is a 
multipurpose new regenerative material that can be used as a bone graft substitute because of its biocompatibility, lack of disease transfer risks, ease of use, unlimited availability, cost-effectiveness, efficiency and also it can be prepared in a very economical way. The minerals of ESP when come in contact with enamel caries-like lesions; they diffuse into the superficial layer and obstruct the surface porosities (14). In 2016, Haghgoo et al. (10) reported that ESP solution can be applied in preventive dentistry as a remineralizing agent and it can be used as a supplement or even an alternative to fluoride.

Novamine is a known synthetic component of bio-active glass (15). The bioactivity of the glass is extremely related to the surface growth rate of hydroxyapatite (HA) layer which is considered the main mineral phase of teeth. It consists of silica, calcium, phosphorus and sodium ions. When they come in contact with saliva, they bind to the tooth structure and initiate the remineralization process (16). Taha et al. in 2017 (17) systematically reviewed the effect of bioactive glasses on enamel remineralization and concluded that bioactive glasses had the ability to enhance enamel remineralization more effectively than other topical remineralizing agents regardless of its formulation or mode of application technique.

The aim of this is to evaluate the remineralizing effect of eggshell powder and novamine on initial caries-like lesions in young permanent teeth compared to fluoride. The null hypothesis tested is that there is no difference between the remineralizing effect of eggshell powder and novamine on initial caries-like lesions in young permanent teeth compared to fluoride.

\section{MATERIALS AND METHODS}

This study was an experimental in- vitro study/ which was approved by the Scientific Research Ethical Committee, Faculty of Dentistry, Alexandria University, Egypt. It was performed in the Departments of Pediatric Dentistry and Dental Public Health, Oral Biology and Dental Materials in Faculty of Dentistry, Department of Geology in Faculty of Science and Department of Production in Faculty of Engineering, Alexandria University.

\section{Sample size estimation}

The minimal sample size was calculated based on a study aimed to evaluate the remineralization potential of enamel surface lesion using chicken egg shell powder (CESP) solution. Mony et al., (18) (2015) reported microhardness values for all the 4 groups of their study. A sample size of 32 teeth per group (number of groups $=3$ ) (total sample size=96) or 16 measurements (half-tooth) per subgroup (number of subgroups =6) (total sample size = 192 half-tooth), each subgroup was measured by 2 different devices, was the enough required sample, as statistically significant with $80 \%$ power and at a significance level of 95\%(accepted alpha of 0.05). Sample size per group did not need to be increased to control for attrition bias. The sample size was calculated using GPower version 3.1.9.2.

\section{Sample}

Ninety six human premolar teeth extracted for orthodontic reasons were collected from Public Hospitals, Department of Orthodontics, Faculty of Dentistry, Alexandria University and
Private Dental Clinics. The sample was randomly divided according to exposure media into three equal groups (I, II and III). Each group was further subdivided into two subgroups by sectioning the teeth of each group. Subgroups IA, IIA and IIIA were treated by the agents eggshell powder, novmine and fluoride respectively and served as experimental subgroups, while subgroups IB, IIB and IIIB were left untreated and served as negative control.

\section{Criteria of teeth selection}

Teeth were selected according to the following criteria:

1. Young permanent teeth free from caries.

2. No enamel cracks.

3. No developmental defects.

\section{Preparation of the teeth specimens}

Teeth were thoroughly cleaned using fluoride free pumice and were stored in normal saline solution until required for use. Teeth were dried, and then squares of self-adhesive labels $4 \times 4 \mathrm{~mm}$ were stuck at the center of the buccal surface of each tooth. All teeth surfaces were coated with acid-proof nail varnish. Then, the adhesives were removed exposing only a small window of enamel.

The crown of each tooth was separated from its root using a diamond disc mounted on a straight hand piece then each crown was sectioned longitudinally in a buccolingual direction through the center of the window into two equal halves; a mesial half and a distal half (192 specimens). Each specimen in the control group was the other half of the same tooth in the test group.

Teeth that were assessed by Vickers microhardness tester were mounted in a self-cure acrylic resin inside cylindrical plastic mold. The buccal surface of each tooth specimen was set perpendicular to the long axis of the block.

Remineralizing agent's formulation

The novamine toothpaste (GSK consumer Healthcare, Brentford, U.K) contained: Calcium Sodium Phosphosilicate, Glycerin, polyethylene glycol ester-8, Hydrated Silica, Cocamidopropyl Betadine, Sodium Methyl Cocoyl Taurate, Aroma, Titanium Dioxide, Carbomer, Sodium Saccharin, Limonene and $1450 \mathrm{ppm}$ Sodium Fluoride. Fluoride tooth paste (B\&S Healthcare, Ruislip, UK) contained: 5000 ppm Sodium Fluoride, 70\% Sorbitol solution, Silica dental type, Precipitated Silica dental type, Macrogol 600, Tetrapotassium Pyrophosphate, Xanthan gum, Sodium Benzoate, Sodium Laurilsulfate, Spearmint Flavouring, Saccharin Sodium, Brilliant Blue FCF and Purified water. Eggshell powder (cdVet Germany, dispatched from U.K.). Preparation of egg shell powder solution: $10 \%$ solution of egg shell powder solution was prepared by dissolving 10 grams of egg shell powder in $100 \mathrm{ml}$ of distilled water (10).

\section{Demineralization phase: (Caries-like lesion formation)}

Each tooth specimen was immersed in a demineralizing solution $(10 \mathrm{ml})$ at $37^{\circ} \mathrm{C}$ for 72 hours without stirring in order to produce artificial carious lesions (white spot lesion without cavitation) (14). After the lesion formation, teeth specimens were rinsed with distilled water and stored in artificial saliva for 7 days (18).

Remineralization phase:

For Subgroups IA: Each specimen was treated with eggshell powder solution for 3 minutes. 
For subgroup IIA and IIIA: Toothpastes were applied with a microbrush according to the manufacturer's instruction for 3 minutes.

Then specimens were rinsed with distilled water and stored in the artificial saliva (19). These procedures were performed once/day/ for 7 days.

For Subgroups IB, IIB and IIIB: Each specimen was left untreated and stored in artificial saliva.

After 7 days, all specimens were rinsed with distilled water and prepared for final evaluation.

\section{Methods of assessment of enamel surface}

Half of the specimens were randomly selected for assessment by Vickers microhardness tester and the other half was assessed by Polarized light microscope.

\section{1- Vickers Microhardness Device}

Microhardness testing was done before any cariogenic challenge (initial base line assessment), after initial caries formation (second assessment) and at the end of the study (final assessment). A load of $50 \mathrm{~g}$ was applied to the surface of the specimens for10 seconds. Five indentations were equally placed over a circle of 1-mm diameter at the cervical third of the specimens. The surface microhardness was obtained using the following equation: $\mathrm{HV}=1.854 \mathrm{P} / \mathrm{d} 2$ where, $\mathrm{HV}$ is Vickers hardness in Kef/mm2, $\mathrm{P}$ is the load in Kef and d is the length of the diagonals in mm (20-22).

\section{2- Polarized light microscope}

At the end of the study, from each subgroup (IA, IIA and IIIA), 16 specimens and their corresponding controls (IB, IIB and IIIB) were evaluated quantitatively (mean lesion depth) and qualitatively (histologically) using polarized light microscope.

Thin longitudinal ground sections of about $15 \mu \mathrm{m}$ thickness were prepared. Each specimen preparation was done on a rotary lathe and then manually ground on wet glass plate with aluminum oxide $\left(\mathrm{AL}_{2} \mathrm{O}_{3}\right)$ powder with different granulations. Each ground section was washed under running water then passed in ascending grades of alcohol (50, 70, 90 and $100 \%)$. Xylol was used for clearance. Canada balsam was the mounting medium used to hold the specimen in place between the slipcover and the glass slide.

\section{Lesion depth evaluation: (Quantitative evaluation)}

The subsurface depth measurements were evaluated using software (image J.46) (23). The readings by the software were represented in pixel unit. To turn the pixel unit into millimeter (mm) unit, a photomicrograph was taken to a known $2 \mathrm{~mm}$ graduated slide of Olympus microscope with the same magnification for all specimens (X40) as a reference slide. The reference slide was projected onto the computer image processing software (Image J 46) as a scale. After setting the scale by the software to get the readings in $\mathrm{mm}$, the results were all recorded in micrometers $(\mu \mathrm{m})$ by multiplying the numbers in thousand. The mean depth of the enamel lesion of each specimen was measured by averaging of three lines: one at each side and one at the center of the lesion within the subsurface of the lesion body, perpendicular to the outer layer of the enamel surface and extending to the translucent band.

\section{Histological evaluation: (Qualitative evaluation)}

Qualitative evaluation was used to describe the interpretation of enamel birefringence and the course of the enamel rods. The different sections were examined by the polarized microscope to evaluate the changes in enamel as a result of demineralization and remineralization process. Photomicrographs were taken with a digital camera with magnification of X40 (eyepiece X10 \& objective lens X4) to achieve comparison in histological features between the test and control specimens. Furthermore, they were compared with the reference section.

\section{Statistical analysis:}

Data were collected and entered to the computer using SPSS program for statistical analysis (version 25.0). Normality was checked using descriptive statistics, plots (histogram and box plot) and Shapiro Wilk test.

Differences in lesion depth and enamel microhardness between test and control in each group were analyzed using parametric test; Student's t test and the non-parametric test; Mann-Whitney U test. Meanwhile, differences between the three remineralizing agents were assessed by using ANOVA for normally distributed data and Kruskal Wallis $\mathrm{H}$ test for the not normally distributed. The level of statistical significance was set at 0.05 . The level of statistical significance was set at 0.05 .

Percent difference of the lesion depth and enamel microhardness among the three groups relative to their controls was calculated according to the formula [(lesion depth in test-lesion depth in control)/lesion depth in control] $\mathrm{x} 100$ and the same for enamel microhardness. Post hoc tests were needed for comparison between percent differences of enamel microhardness among three groups. Dunn's pairwise comparisons were carried out for the three pairs of groups (24).

\section{RESULTS}

\section{Quantitative results}

There was a statistically significant difference in mean enamel surface microhardness between subgroup IA (egg shell powder) and subgroup IB (its control) $(\mathrm{P}=0.004)$. There was a statistically significant difference in mean enamel surface microhardness between subgroup IIA (novamine) and subgroup IIB (its control) $(\mathrm{P}=0.001)$. Whereas, there was no statistically significant difference between subgroup IIIA (fluoride) and its control where $\mathrm{P}=0.54$. Using Kruskal Wallis $\mathrm{H}$ test there was a statistically significant difference in mean percent difference values of enamel microhardness among three groups $(\mathrm{P}<0.001)$, with group II having a higher mean percent difference value of enamel microhardness $12.47 \pm 20.99$ than group I and III $(9.17 \pm 12.06,1.61 \pm 0.49)$, (Table 1).

Table 1: Showing mean enamel surface microhardness values between test and control in each group and mean percent difference values of enamel surface microhardness among three groups relative to their controls.

\begin{tabular}{|l|c|c|c|}
\hline \multicolumn{1}{|c|}{$\begin{array}{c}\text { Enamel } \\
\text { microhardness }\end{array}$} & Test & Control & P value \\
\hline $\begin{array}{l}\text { Egg shell powder } \\
\text { : Mean } \pm \text { SD }\end{array}$ & $270.63 \pm 34.62$ & $248.06 \pm 19.54$ & $0.004^{*}$ \\
\hline $\begin{array}{l}\text { Novamine : } \\
\text { Mean } \pm \text { SD }\end{array}$ & $273.46 \pm 18.48$ & $243.13 \pm 61.43$ & $<0.001^{*}$ \\
\hline $\begin{array}{l}\text { Fluoride : } \\
\text { Mean } \pm \text { SD }\end{array}$ & $269.03 \pm 19.67$ & $246.78 \pm 19.87$ & 0.54 \\
\hline & Group I \% & Group II \% & $\begin{array}{c}\text { Group III } \\
\%\end{array}$ \\
\hline
\end{tabular}




\begin{tabular}{||c|c|l|r|}
\hline Mean \pm SD & $9.17 \pm 12.06$ & $12.47 \pm 20.99$ & $1.61 \pm 0.49$ \\
\hline P value & \multicolumn{3}{|c|}{$<0.001^{*}$} \\
\hline
\end{tabular}

*: Significant difference (P $\square 0.05)$.

Post-Hoc test for multiple comparisons between mean percent difference of enamel microhardness among three groups using Dunn's pairwise test showed that there was a statistically significant difference between group I and III $(\mathrm{P}=0.014)$ and between group II and III $(\mathrm{P}=0.001)$. Whereas, there was no statistically significant difference between group I and group II ( $\mathrm{P}=0.022)$, (Table 2).

Table 2: Showing post hoc test for multiple comparisons between the mean percent differences of enamel microhardness among three groups.

\begin{tabular}{||l|c|c||}
\hline \multicolumn{1}{|c|}{ Groups } & Compared to & P value \\
\hline \multirow{2}{*}{ Group I } & Group II & 0.022 \\
\cline { 2 - 3 } & Group III & $0.014^{*}$ \\
\hline Group II & Group III & $0.001^{*}$ \\
\hline
\end{tabular}

*Statistically significant with adjustment for multiple comparison for multiple testing $(\mathrm{P}<0.016)$

There was a statistically significant difference in mean lesion depth between subgroup IA (egg shell powder) and subgroup IB (its control) $(\mathrm{P}<0.001)$. There was a statistically significant difference in mean lesion depth between subgroup IIA (novamine) and subgroup IIB (its control) $(\mathrm{P}<0.001)$. Whereas, there was no statistically significant difference between subgroup IIIA (fluoride) and its control $(\mathrm{P}=0.36)$. Using Kruskal Wallis $\mathrm{H}$ test there was no statistically significant difference in mean percent difference values of lesion depth among three groups ( $\mathrm{P}=0.15$ ), (Table 3 ).

Table 3: Showing mean lesion depth values between test and control in each group and mean percent difference values of lesion depth among three groups relative to their controls.

\begin{tabular}{||c|c|c|c||}
\hline $\begin{array}{c}\text { Lesion } \\
\text { depth }\end{array}$ & Test & Control & P value \\
\hline $\begin{array}{l}\text { Egg shell } \\
\text { powder : } \\
\text { Mean } \pm \text { SD }\end{array}$ & $95.63 \pm 56.09$ & $203.13 \pm 61.43$ & $<0.001^{*}$ \\
\hline $\begin{array}{c}\text { Novamine } \\
\text { Mean } \pm \text { SD }\end{array}$ & $79.38 \pm 26.70$ & $236.25 \pm 61.19$ & $<0.001^{*}$ \\
\hline $\begin{array}{l}\text { Fluoride : } \\
\text { Mean } \pm \text { SD }\end{array}$ & $76.25 \pm 34.23$ & $190.00 \pm 53.54$ & 0.36 \\
\hline & Group I \% & Group II \% & Group III \% \\
\hline Mean \pm SD & - & $-62.96 \pm 18.12$ & $-59.15 \pm 14.04$ \\
\hline P value & $54.21 \pm 16.05$ & 0.15 & \\
\hline
\end{tabular}

*: Significant difference $(\mathrm{P}<0.05)$.

\section{Qualitative results}

\section{Subgroup IA (Eggshell powder solution)}

Most of the representative lesions exhibited noticeable reduction in the depth of the lesion seen in subgroup IB. Other specimens showed complete absence of the dark bands. This appeared in the form of negative birefringence emphasizing the effect of this solution for remineralization, (Figure 1A, Figure 1B).

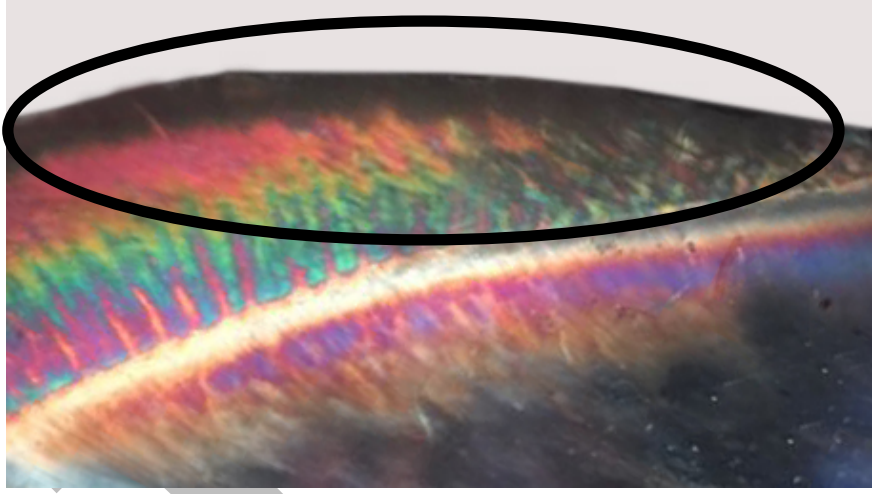

Figure 1A: Polarized light photomicrograph of a longitudinal ground section of the control specimen (subgroup IB) exhibiting a dark and deep demineralized enamel segment, magnification X40.

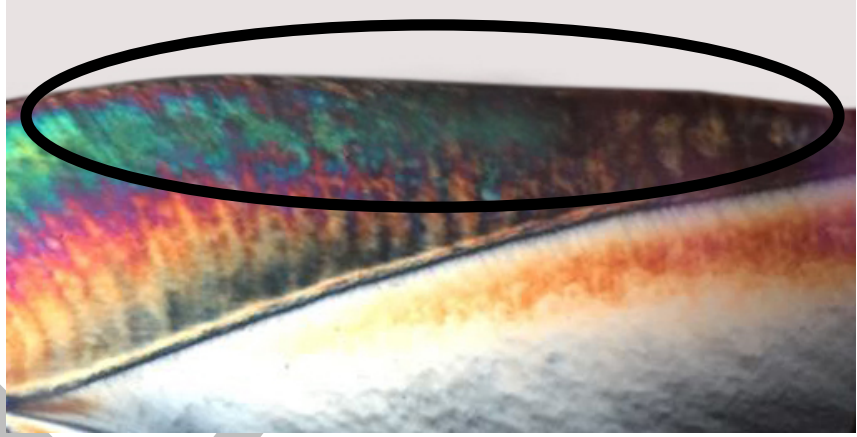

Figure 1B: Polarized light photomicrograph of a longitudinal ground section of enamel treated with eggshell powder solution (subgroup IA) showing homogenous remineralization of the caries like lesion comparable to the control specimen figure 33-A, magnification X40.

\section{Subgroup IIA (Novamine toothpaste)}

In this subgroup the observed degree of remineralization was comparable to that seen in subgroup IA. Almost all the representative lesions showed absence of the dark zones that were seen prior to remineralization and this emphasized the remineralization effect of this paste, (Figure 2A, Figure 2B).

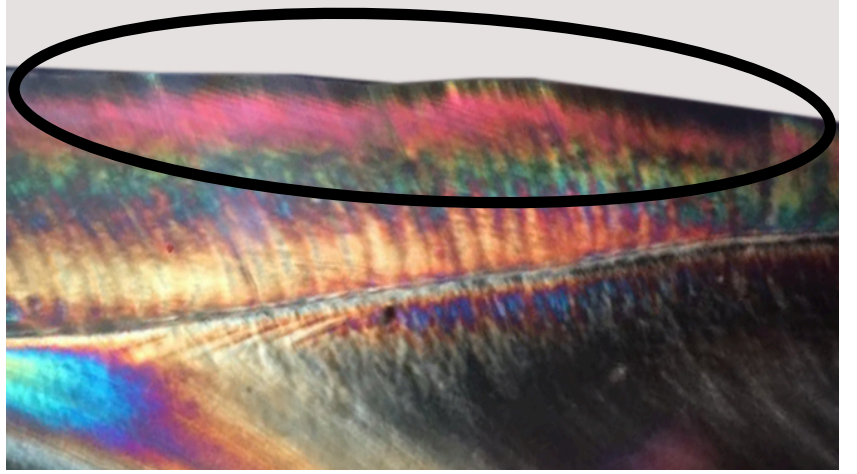

Figure 2A: Polarized light photomicrograph of a longitudinal ground section of the control specimen 
(subgroup IIB) showing dark demineralization segment, magnification X40

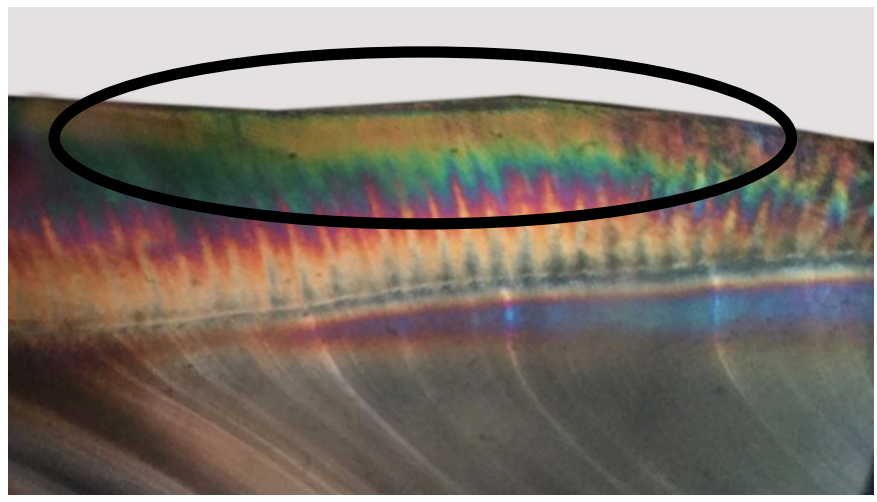

Figure 2B: Polarized light photomicrograph of a longitudinal ground section of enamel treated with novamine toothpaste (subgroup IIA) showing complete homogenous extensive remineralization of the caries like lesion, magnification X40

\section{Subgroup IIIA (Fluoride toothpaste)}

The enamel showed variable degrees of remineralization, but the body of the lesions showed less degree of enamel remineralization than in subgroups IA and IIA, (Figure 3AFigure 3B).

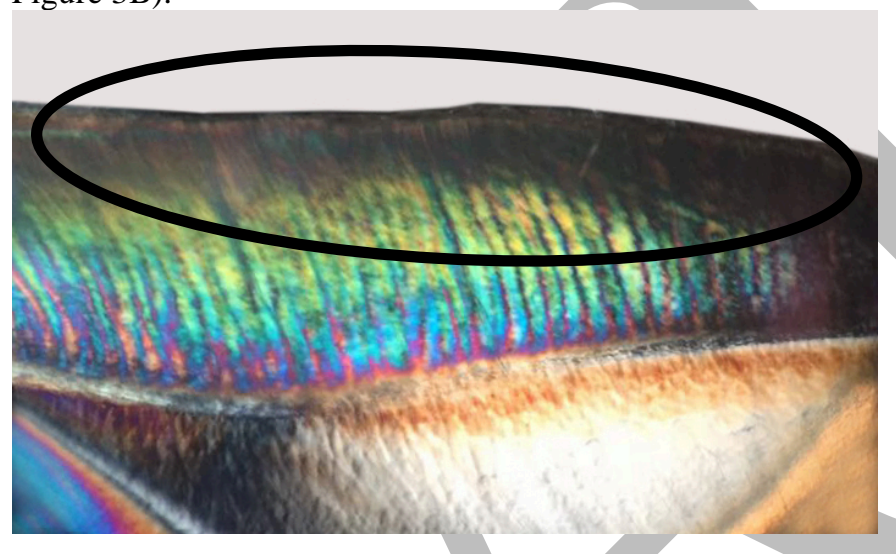

Figure 3A Polarized light photomicrograph of a longitudinal ground section of a control specimen (subgroup IIIB) showing dark demineralization segment, magnification X40.

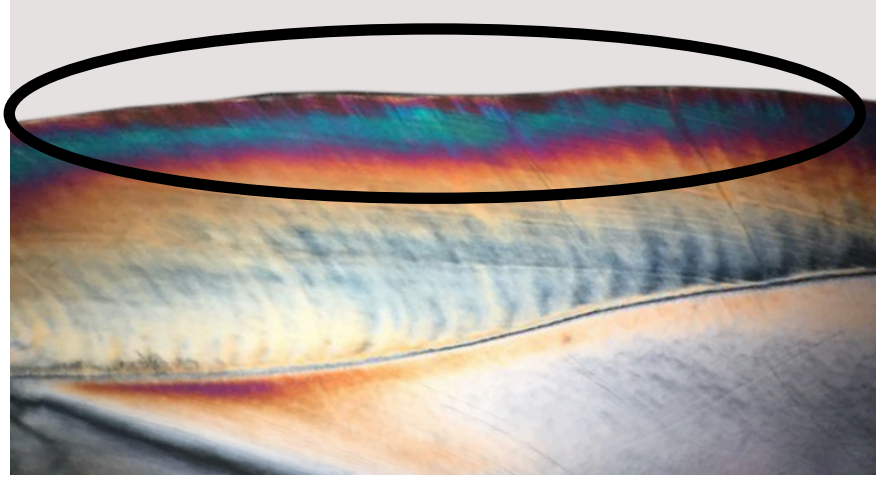

Figure 3B: Polarized light photomicrograph of a longitudinal ground section of enamel treated with fluoride toothpaste (subgroup IIIA) showing a decrease in the extent of the lesion, magnification $\mathrm{X} 40$.

\section{DISCUSSION}

In the present study, the quantitative evaluation of the enamel surface was carried out by measuring the surface microhardness. Microhardness evaluation is a convenient method for a material having non homogenous, fine microstructure and prone to cracking like enamel. Surface microhardness indentation provides relatively a simple, reliable, non-destructive and rapid method for evaluation of remineralization changes of the tooth surface (18).

The results obtained in the present study revealed that there was a statistically significant difference in the mean enamel surface microhardness between subgroup IA (treated with eggshell powder solution) and subgroup IB (its control). This finding was in agreement with Mony et al. in 2015 (18) who concluded that eggshell powder has the potential to favor remineralization due to its high $\mathrm{pH}$ and rich bioavailable calcium content. It was also supported by Haghoo et al. in 2016 (10) who revealed that eggshell solution can be used as a remineralizing agent for incipient enamel carious lesions and it is as effective as nano-hydroxyapatite for enamel remineralization. Moreover, Yaberi and Haghoo in 2018 (25) reported that microhardness of the enamel significantly increased after treatment with eggshell extract solution.

Statistical analysis of the present study indicated that there was a statistically significant difference in the mean enamel surface microhardness between subgroup IIA (treated with novamine toothpaste) and subgroup IIB (its control). This result was in agreement with Golpayegani et al. in 2012 (26) who concluded that novamine dentifrice has a greater effect on remineralization of carious-like lesions. Results of a study conducted by Taha et al. in 2017 (17) was also in agreement with the results of the present study. They reported that bioactive glass has the ability to enhance enamel remineralization regardless of its formulation or mode of application technique. Moreover, Huang et al. in 2018 (27) affirmed that novamine can remineralize the demineralized dentin specimens and occlude the dentinal tubules in the hydroxyapatite-like crystal structure.

Although there was a slight increase in enamel surface microhardness in subgroup IIIA (treated with fluoride toothpaste) than in subgroup IIIB (its control); this difference was not statistically significant. The possible explanation of this result is that, fluoride is not considered as a source of calcium (Ca) as with novamine and eggshell powder. Its action is limited by the availability of phosphate (P) and Ca ions (28). The real remineralizing effect of fluoride is to enhance the redeposition of $\mathrm{Ca}$ and $\mathrm{P}$ ions that are present in the biofilm of the demineralized enamel when the $\mathrm{pH}$ of the oral cavity rises (6). This interpretation was further supported by Reynolds et al. in 2008 (29) who proved that $\mathrm{Ca}$ and $\mathrm{P}$ ions from saliva are important factors in the remineralization of previously demineralized enamel by fluoride. It was also in agreement with Neel et al. in 2016 (30) who concluded that fluoride acted as a catalyst for 
diffusion of $\mathrm{Ca}$ and $\mathrm{P}$ ions in the tooth which aided in remineralization of crystals in the lesion.

In the current study, there was no significant difference in mean percent difference of enamel microhardness between group I (eggshell powder) and group II (novamine). On the other hand, they showed significant higher mean percent difference of enamel microhardness than group III (fluoride). These findings were in agreement with Golpayegani et al. in 2012 (26) who reported that novamin dentifrice appears to have a greater effect on remineralization of carious-like lesions when compared to that of fluoride containing dentifrice. On the other hand, these results were not in line with the findings of Mony et al. in 2015 (18) who, revealed that fluoride showed more remineralization on early enamel carious lesions than eggshell powder. The difference with the current results could be due to the difference in the type of toothpaste used in both studies.

This study is a pioneer work to use polarized light microscope (PLM) to evaluate remineralizing effect of eggshell powder and novamine in comparison to fluoride. PLM was used for qualitative and quantitative evaluation of the lesion changes in conjunction with microhardness analysis, because it is extremely sensitive to small changes in the optical properties. It can qualitatively show the areas of mineral loss and mineral gain represented by the visualization of areas with different porosities and birefringence (31).

In the present study, qualitative data obtained from PLM showed that most of the representative lesions treated by eggshell powder solution or novamine toothpaste exhibited a shift from positive to negative birefringence with a striking reduction in the depth of the lesion. Other specimens showed complete absence of the dark bands within the body of the lesion that is present in the control specimens. This was proven quantitatively by the significant reduction in the mean lesion depth of test subgroups IA (egg shell powder) and IIA (novamine) in comparison with their corresponding controls. Qualitative data revealed that the enamel lesions of subgroup IIIA (treated by fluoride toothpaste) showed variable degrees of remineralization, but the body of the lesions showed less degree of enamel remineralization than in subgroups IA and IIA. This was proven quantitatively as there was no significant lesion depth reduction between test subgroup IIIA (fluoride) and its control. This finding is not in a line with the finding of Pulido et al. in 2008 (32) who reported that the highly concentrated sodium fluoride (NaF) 5000 ppm reduced lesion depth and had a protective effect against demineralization. Moreover, Prabhakar et al. in 2013 (33) concluded that NaF 5000ppm showed significant percentage of remineralization, measured as a decrease in lesion depth. The difference with the current results could be due to the use of different methodology.

Although there was a significant difference in mean percent values of enamel microhardness among the three groups, there was no statistically significant difference in the mean percent values of the lesion depth among them. The possible explanation of these results is that, histologically, the overall lesion depth usually did not change after remineralization because the reduction of the pore volume inside the body of the lesion is due to the reduction in the overall pore size but the number of pores remained high. In addition to that, due to volume loss from demineralization, the lesion body did not repair by an organized crystal arrangement (34). Moreover, remineralization is a very slow process. In fact, while subsurface lesions remineralize in vitro within weeks, years are required for complete remineralization in vivo (35). Several studies have confirmed that the remineralization process restores minerals to a greater extent near the surface than in the underlying body of the lesion (36-38). This explanation was supported by ten Cate in 2008 (39) who concluded that the effect of the tested agents were found in the outer enamel and did not significantly affect mineral precipitation in the inner enamel and dentin. It was also in agreement with Kim et al. in 2013 (40) who, proved that the histological observations of lesions by PLM revealed higher recovery percentage for shallow lesions than deep lesions.

Based on the overall qualitative and quantitative results of the present study, it could be concluded that both egg shell powder and novamine can be used as remineralizing agents. Moreover, they appear to have a greater effect on remineralization of initial caries-like lesions when compared to fluoride in young permanent teeth.

The limitations of this study were the difficulty in reproducing the oral environment, cariogenic bacteria and different salivary compounds which might influence the outcome during application of these agents. In addition, the present study was limited to a 7 days period, while the de/remineralization processes are long-term processes. Furthermore, in vivo salivary flow and turnover cannot be sufficiently mimicked in vitro.

Within the limitations of the current study, it is indicated that eggshell powder and novamine showed better remineralization capacity than fluoride, this rejects the proposed null hypothesis in the present study.

\section{CONCLUSION}

Based on the results of the present study and its limitations, it could be concluded that:

1. Both egg shell powder and novamine can be used as remineralizing agents.

2. Both egg shell powder and novamine appear to have a greater effect on remineralization of initial caries-like lesions when compared to fluoride in young permanent teeth.

\section{CONFLICT OF INTEREST}

The authors declare that they have no conflict of interest.

\section{REFERENCES}

1. Jacob M. Models and role models. Caries Res. 2015;49:3-10.

2. Petersen PE. The World Oral Health Report 2003: continuous improvement of oral health in the 21st century-the approach of the WHO Global Oral Health Programme. Community Dent Oral Epidemiol. 2003;31:3-24.

3. Selwitz RH, Ismail AI, Pitts NB. Dental caries. Lancet. 2007;369:51-9. 
4. Peters MC. Strategies for noninvasive demineralized tissue repair. Dent Clin North Am. 2010;54:507-25.

5. Abbas H. Minimal intervention approaches in remineralizing early carious lesions. J Am Sci. 2012;8:709-17.

6. Cury JA, Tenuta LMA. Enamel remineralization: controlling the caries disease or treating early caries lesions? Braz Oral Res. 2009;23:23-30.

7. Buzalaf MAR. Fluoride and the oral environment. Basel, Switzerland, New York: Karger; 2011.

8. Wright JT, Hanson N, Ristic H, Whall CW, Estrich CG, Zentz RR. Fluoride toothpaste efficacy and safety in children younger than 6 years: a systematic review. J Am Dent Assoc. 2014;145:182-9.

9. Stadelman WJ. Eggs and egg products. In: Francis FJ (ed). Encyclo-pedia of foof science and technology. $2^{\text {nd }}$ ed. New York: John, Wiley and Sons; 2000. pp 593-9.

10. Haghgoo R, Mehran M, Ahmadvand M, Ahmadvand MJ. Remineralization Effect of Eggshell versus Nanohydroxyapatite on Caries-like Lesions in Permanent Teeth (In Vitro). J Int Oral Health. 2016;8:435-9.

11. Vestergaard P, Jorgensen N, Schwarz P, Mosekilde L. Effects of treatment with fluoride on bone mineral density and fracture risk-a meta-analysis. Osteoporosis Int. 2008;19:257-68.

12. Krishna DSR, Siddharthan A, Seshadri S, Kumar TS. A novel route for synthesis of nanocrystalline hydroxyapatite from eggshell waste. J Mater Sci Mater Med. 2007;18:1735-43.

13. Kattimani VS, Chakravarthi PS, Kanumuru NR, Subbarao VV, Sidharthan A, Kumar TS, et al. Eggshell derived hydroxyapatite as bone graft substitute in the healing of maxillary cystic bone defects: a preliminary report. J Int Oral Health. 2014;6:15-9.

14. Huang S, Gao S, Yu H. Effect of nano-hydroxyapatite concentration on remineralization of initial enamel lesion in vitro. Biomed Mater. 2009;4:034104.

15. Hench LL. The story of Bioglass ${ }^{\circledR}$. J Mater Sci Mater Med. 2006;17:967-78.

16. Lata S, Varghese N, Varughese JM. Remineralization potential of fluoride and amorphous calcium phosphatecasein phospho peptide on enamel lesions: An in vitro comparative evaluation. J Conserv Dent. 2010;13:42-6.

17. Taha AA, Patel MP, Hill RG, Fleming PS. The effect of bioactive glasses on enamel remineralization: A systematic review. J Dent. 2017;67:9-17.

18. Mony B, Ebenezar AR, Ghani MF, Narayanan A. Effect of Chicken Egg Shell Powder Solution on Early Enamel Carious Lesions: An Invitro Preliminary Study. J Clin Diagn Res. 2015;9:ZC30-2.

19. Darshan H, Shashikiran N. The effect of McInnes solution on enamel and the effect of Tooth mousse on bleached enamel: An in vitro study. J Conserv Dent. 2008;11:86-91.

20. Lupi-Pegurier L, Muller M, Leforestier E, Bertrand M, Bolla M. In vitro action of Bordeaux red wine on the microhardness of human dental enamel. Arch Oral Biol. 2003;48:141-5.
21. Toledano M, Osorio R, Osorio E, Prati C, Carvalho RM. Microhardness of acid-treated and resin infiltrated human dentine. J Dent. 2005;33:349-54.

22. Abdullah A, Strafford S, Brookes S, Duggal M. The effect of copper on demineralization of dental enamel. J Dent Res. 2006;85:1011-5.

23. da Camara DM, Miyasaki ML, Danelon M, Sassaki KT, Delbem ACB. Effect of low-fluoride toothpastes combined with hexametaphosphate on in vitro enamel demineralization. J Dent. 2014;42:256-62.

24. Dinno A. Nonparametric pairwise multiple comparisons in independent groups using Dunn's test. Stata J. 2015;15:292-300.

25. Yaberi M, Haghgoo R. A comparative study of the effect of nanohydroxyapatite and eggshell on erosive lesions of the enamel of permanent teeth following soft drink exposure: A randomized clinical trial. J Int Oral Health. 2018;10:176-9.

26. Golpayegani MV, Sohrabi A, Biria M, Ansari G. Remineralization effect of topical NovaMin versus sodium fluoride $(1.1 \%)$ on caries-like lesions in permanent teeth. J Dent. 2012;9:68-75.

27. Huang X, Li R, Feng Y, Wang Y. Remineralization of demineralized dentin induced by bioactive glass NovaMin. Zhong Nan Da Xue Xue Bao Yi Xue Ban. 2018;43:61924.

28. Elkassas D, Arafa A. Remineralizing efficacy of different calcium-phosphate and fluoride based delivery vehicles on artificial caries like enamel lesions. J Dent. 2014;42:466-74.

29. Reynolds E, Cai F, Cochrane N, Shen P, Walker G, Morgan M, et al. Fluoride and casein phosphopeptideamorphous calcium phosphate. J Dent Res. 2008;87:3448.

30. Neel EAA, Aljabo A, Strange A, Ibrahim S, Coathup M, Young AM, et al. Demineralization-remineralization dynamics in teeth and bone. Int $\mathrm{J}$ Nanomedicine. 2016;11:4743-63.

31. Kumar V, Itthagarun A, King N. The effect of casein phosphopeptide-amorphous calcium phosphate on remineralization of artificial caries-like lesions: an in vitro study. Aust Dent J. 2008;53:34-40.

32. Pulido M, Wefel J, Hernandez M, Denehy G, GuzmanArmstrong S, Chalmers J, et al. The inhibitory effect of MI paste, fluoride and a combination of both on the progression of artificial caries-like lesions in enamel. Oper Dent. 2008;33:550-5.

33. Prabhakar A, Manojkumar AJ, Basappa N. In vitro remineralization of enamel subsurface lesions and assessment of dentine tubule occlusion from $\mathrm{NaF}$ dentifrices with and without calcium. J Indian Soc Pedod Prev Dent. 2013;31:29-35.

34. Jones R, Fried D. Remineralization of enamel caries can decrease optical reflectivity. J Dent Res. 2006;85:804-8.

35. Arends J, Gelhard TBFM. In vivo remineralization of human enamel. In: leach SA, Edgard WM. Demineralization and remineralization of the teeth. Oxford: IRL Press Limited; 1983. pp 1-16.

36. Jongebloed W, Arends J. Remineralization of artificial enamel lesions in vitro. Caries Res. 1981;15:60-9. 
37. Ten Cate J. Remineralization of artificial enamel lesions in vitro. III. A study of the deposition mechanism. Caries Res. 1980;14:351-8.

38. Iijima Y, Takagi O, Ruben J, Arends J. In vitro remineralization of in vivo and in vitro formed enamel lesions. Caries Res. 1999;33:206-13.

39. Ten Cate J. Remineralization of deep enamel dentine caries lesions. Aust Dent J. 2008;53:281-5.

40. Kim HE, Kwon HK, Kim BI. Recovery percentage of remineralization according to severity of early caries. Am J Dent 2013;26:132-6. 